This document is the accepted manuscript version of a published work that appeared in final form in the British Journal of Midwifery, copyright (C) MA Healthcare, after peer review and technical editing by the publisher. To access the final edited and published work see

http://www.magonlinelibrary.com/doi/10.12968/bjom.2016.24.1.66

Midwifery in the $21^{\text {st }}$ Century:

Are our students prepared for the challenge?

\begin{abstract}
The role of the midwife is emotionally and physically challenging: birth-rates are increasing; there are staff shortages and increasingly more complex cases to coordinate care for (RCM, 2015). There are also professional (NMC, 2015a) and political (eg Chief Nursing Officers of England, Northern Ireland, Scotland and Wales, 2010) requirements to be met, and all this in the context of practising in line with our core value of being 'with woman' and providing her with individualised, high quality, evidence-based care.
\end{abstract}

Whilst such demands drive some midwives to leave citing stress; burnout; compassion fatigue and emotional exhaustion as causes (Curtis et al., 2006), there are others who stay in the profession. Such midwives have developed strategies to cope with the complex and varied stressors of their role: they demonstrate resilience. The future of maternity services in the United Kingdom (UK) is dependent on the retention of resilient midwives and so it is important that the characteristics of such midwives are explored to ascertain whether resilience is a personal trait or whether it can be learned. To this end, in 2013 the Royal College of Midwives (RCM) funded the first research project in the UK to investigate resilience in midwifery (Hunter and Warren, 2013).

As a midwifery lecturer and personal academic tutor, I have a vested interest in the wellbeing and success of student midwives both in the university and practice settings. This article will provide an overview of the clinical, professional and political stressors qualified midwives have to deal with on a daily basis in order to understand the environment student midwives are exposed to when working under the tutelage of their midwife mentor. It will also consider the relevance of Hunter and Warren's findings in the context of midwifery pre-registration education, since the future of midwifery practice in the UK depends on the recruitment, retention and successful qualification of student midwives who are adequately prepared to cope with the complex emotional and physical demands of their chosen profession.

Keywords: resilience; midwives; student midwives; pre-registration midwifery 
education

\section{What is resilience?}

Resilience can be defined as 'the ability to maintain personal and professional wellbeing in the face of ongoing work stress and adversity' (McCann et al., 2013:61). Stress is an individual's reaction to change: positive stress is beneficial as it can be motivational, thereby contributing to successful outcomes; conversely negative stress can impact on the individual's confidence and selfesteem (Rodder, 2015; Seaward, 2006). The literature conceptualises resilience through a number of lenses: Collins (2007) suggests it is both a personal trait and the ability to adapt to adverse situations. Luthar and Cicchetti, 2000 argue that suggesting an individual is inherently resilient is misleading as, in their view; it is a process whereby the individual learns to be resilient through coping with adverse situations. In addition to definitions of resilience as a personal quality and a learning process, Masten and Coatsworth (1998) view it as an outcome: the individual becomes competent in the skill of dealing with adversity. Notwithstanding the conceptualisation of resilience by trait, process or outcome, it is widely accepted that it is the positive adaptation to an adverse situation (Adamson et al., 2014).

\section{Stressors in contemporary maternity services}

The midwife is the lead professional in providing care and support to women throughout the childbirth continuum and co-ordinates care in complex cases where a multi-professional approach is required. There were 695,233 live births in England and Wales in 2014 (Office for National Statistics (ONS), 2015), with an overall increase of 23\% between 2001-2012 (National Audit Office, 2013). In addition to a rising birth-rate, midwifery practice is becoming increasingly challenging as a result of a rise in the proportion of 'complex' cases including, but not limited to factors such as older mothers ( $78 \%$ increase in births to women aged 40 and over in England between 2001-2014 (Royal College of Midwives (RCM), 2015); higher rates of multiple births due to fertility treatment; caesarean sections accounting for $25.5 \%$ of all births (Health and Social Care Information Centre, 2013); obesity; pre-existing medical conditions; substance misuse; poverty and immigration. Such social, economic and clinical challenges 
require greater levels of intervention and more complex support packages thereby increasing workplace pressures on the midwife (RCM, 2015; Centre for Workforce Intelligence, 2012; National Institute for Health and Care Excellence (NICE), 2014; National Audit Office, 2013).

In relation to staffing levels, the recommended ratio of midwives to births is one full time equivalent (FTE) midwife per 28 births in hospital/labour wards and 35 to 1 for home births. National Audit Office (2013) statistics showed that in 2012 the ratio was 32.8 births per midwife which signifies a workload above recommended levels. Furthermore, in 2013 there was a shortfall of 2,300 midwives in England (National Audit Office, 2013), which increased to 2,600 in 2014 (RCM, 2015) exacerbated by the increase in part time working and more than $66 \%$ of midwives being over 40 and $25 \%$ over 50 with an average age of 44.

Whilst the number of midwives has increased since 2005 (RCM, 2015), 3,106 $(98 \%)$ of these additional midwives are aged 50 or over with only 66 (2\%) being under the age of 50. Approximately 4,628 midwives will retire between 2010 and 2016 (Centre for Workforce Intelligence, 2012), what is being termed the 'retirement time bomb' by the RCM (2015:2), meaning maternity services will lose a tranche of highly skilled and experienced midwives who, historically, have mentored and supported their less experienced colleagues to develop skills and confidence. It is therefore imperative that measures are taken to support newly qualified midwives to stay in the profession to become expert practitioners and effective mentors. In terms of succession planning, it is also important that student midwives are supported to successfully complete their programme of study to join the workforce.

\section{Professional, political and Service User expectations}

In addition to service demands, the midwife also has professional and political standards to meet to ensure women receive a high quality service. The Nursing and Midwifery Council (NMC) has a remit to protect the health and wellbeing of the public by setting standards of education, training, conduct and performance to ensure the public consistently receives high quality, evidence-based care (NMC, 2015a). 
The midwife is also obliged to practise in line with legislation: Changing Childbirth (Expert Maternity Group, 1993) identified choice, control and continuity of care as the most important elements of maternity care. Subsequent policy documents state that services should be high quality, individualised and woman-centred (Department of Health (DH), 2004; DH/Partnerships for Children, Families and Maternity, 2007). Most recently, the key messages from Midwifery 2020: delivering expectations (Chief Nursing Officers of England, Northern Ireland, Scotland and Wales, 2010) are that women's needs must be met by ensuring they are supported to have a positive and life enhancing transition to parenthood. From the service user's perspective 'a good midwife' should possess attributes such as theoretical knowledge, clinical competency, good interpersonal skills and moral/ethical values in order to provide a service where they feel supported, empowered and informed (Borrelli, 2014). Such high professional, political and service user demands serve to further exacerbate the stressors of overworked, understaffed midwives.

\section{Resilience in midwifery}

stress and workplace adversity [and] contribute to increased sickness rates and poor staff retention

(Hunter and Warren: 2013:4)

Hunter and Warren (2013) used online focus groups to explore the experiences of senior midwives who self-reported as being able to 'bounce back' after a difficult day with the aim of identifying traits or characteristics of resilience. Participants felt they were resilient because they had a strong sense of professional identity and had learned to use a range of coping strategies such as accessing support and having self-awareness and self-preservation to cope with the demands of their workplace. It was anticipated that findings could inform the development of better support systems for all practising midwives in order to reduce attrition rates by better preparing them to deal with the increasingly complex physical and emotional demands of their chosen profession.

\section{Implications for pre-registration midwifery education}

Hunter and Warren (2013) suggested that their findings could have implications for pre-registration midwifery education, with recommendations including the 
implementation of sessions to discuss the realities of practice and strategies to enhance student midwives' emotional awareness of self and others. Reflection was also identified as key to developing resilience, in order to consider the emotional implications of clinical practice as well as its practicalities.

\section{Where do we go from here?}

'When there are not enough midwives it is the quality of the service that women receive that suffers' (RCM, 2015:2), consequently it is important for the future of maternity services that all students who commence their training complete it and qualify as midwives to join the depleting workforce (RCM, 2015). There are currently 92 universities offering approved midwifery courses in England (NMC, 2015b) and just over 2,500 student midwife places were commissioned in England in each of the four years to 2012-13 (National Audit Office, 2013). In an environment with a shortfall in numbers of practising midwives (National Audit Office, 2013) and an impending retirement time bomb (RCM, 2015) it is concerning to see that a proportion of student midwives are failing to complete their courses, with the RCM estimating an approximate attrition rate of $20 \%$ and a further $5-10 \%$ attrition within 18 months of qualification (Centre for Workforce Intelligence, 2012). The Report of Maternity Services in England's figures show that $27 \%$ of midwifery students who should have qualified in 2011-12 failed to complete their programme of study (DH, 2013).

There has to date been no research in the UK specifically focussing on student midwives' construct of resilience and their perceptions of the personal, academic and clinical enablers and barriers to its development. In the absence of primary research into this area, Hunter and Warren's (2013) recommendations for preregistration midwifery education should be carefully considered. If student midwives are supported to develop their resilience during their training they will qualify with the skills to better cope with the professional and emotional demands of their chosen profession. 


\section{References}

Adamson C, Beddoe L, Davys Allyson (2014) Building Resilient Practitioners:

Definitions and practitioner understandings. British Journal of Social Work $4 \mathbf{4}$ 522-541

Borrelli S (2014) What is a good midwife? Insights from the literature. Midwifery 30 3-10

Centre for Workforce Intelligence (2012) Workforce Risks and Opportunities: Midwives. Education Commissioning Risks Summary from 2012. Centre for Workforce Intelligence [online]. Available from:

file://C:/Users/Alison\%20Power/Downloads/WRO\%20ECRS\%202012\%20Midwi ves\%20Mar\%202012.pdf. [Accessed 18.09.15]

Chief Nursing Officers of England, Northern Ireland, Scotland and Wales (2010) Midwifery 2020: delivering expectations. Cambridge: Midwifery 2020 Programme

Collins, S. (2007) Social workers, resilience, positive emotions and optimism. Practice 19 (4) 255-69

Curtis P, Ball L, Kirkham M (2006) Why do midwives leave? (not) being the kind of midwife you want to be. British Journal of Midwifery 14 27-31

Department of Health (DH) (2013) Report of Maternity Services in England. London: The Stationery Office

Department of Health/Partnerships for Children, Families and Maternity (2007) Maternity Matters: choice, access and continuity of care in a safe service. London: DH Publications

Department of Health (DH) (2004) Maternity Standard, National Service Framework for Children, Young People and Maternity Services. London: DH Publications

Expert Maternity Group (1993) Changing Childbirth. Part 1: Report of the Expert Maternity Group. London: Department of Health

Health and Social Care Information Centre (2013) Hospital Episode Statistics. NHS Maternity Statistics 2012-13. Health and Social Care Information Centre [online]. Available from: http://www.hscic.gov.uk/catalogue/PUB12744/nhsmate-eng-2012-13-summ-repo-rep.pdf. [Accessed 25.09.15]

Hunter B, Warren L. (2013) Investigating Resilience in Midwifery: Final report. Cardiff University: Cardiff

Luthar S, Cicchetti D (2000) The construct of resilience: Implications for interventions and social policies. Development and Psychopathology 12 (4) 857-85 
Masten, A. and Coatsworth, J. (1998) The development of competence in favourable and unfavourable environments: Lessons from research on successful children. American Psychologist 5 205-20

McCann C, Beddoe E, McCormick K, Huggard P, Kedge S, Adamson C, Huggard J (2013) Resilience in the health professions: a review of recent literature. International Journal of Wellbeing 3 (1) 60-81

National Audit Office (2013) Maternity Services in England. National Audit Office [online]. Available from: http://www.nao.org.uk/wp-

content/uploads/2013/11/10259-001-Maternity-Services-Book-1.pdf. [Accessed 15.09.15]

National Institute for Health and Care Excellence (NICE) (2014) Pregnancy and complex social factors: a model for service provision for pregnant women with complex social factors. NICE [online]. Available from:

https://www.nice.org.uk/guidance/cg110. [Accessed 19.09.15]

Nursing and Midwifery Council (NMC) (2015a) The Code: professional standards of practice and behaviour for nurses and midwives. London: NMC

Nursing and Midwifery Council (NMC) (2015b) Approved Programmes. NMC [online]. Available from: http://www.nmc.org.uk/education/approvedprogrammes/. [Accessed 16.09.15]

Nursing and Midwifery Council (NMC) (2009) Standards to Support Learning and Assessment in Practice. London: NMC

Office for National Statistics (ONS) (2015) Births in England and Wales, 2014. Office for National Statistics [online]. Available from:

http://www.ons.gov.uk/ons/dcp171778 410897.pdf. [Accessed 19.09.15]

Rodder R (2006) Stress and the student midwife. Royal College of Midwives [online]. Available from: https://www.rcm.org.uk/content/stress-and-thestudent-midwife. [Accessed 13.10.15]

Royal College of Midwives (RCM) (2015) State of Maternity Services Report 2015. Royal College of Midwives. [online]. Available from:

https://www.rcm.org.uk/sites/default/files/RCM\%20State\%20of\%20Maternity\% 20Services\%20Report\%202015.pdf. [Accessed 29.10.15]

Seaward B (2006) Managing Stress. London: Jones and Bartlett Publishers 